\title{
Atmospheric Global Circuit Variations from Vostok and Concordia Electric Field Measurements
}

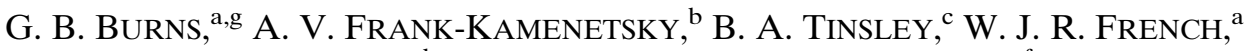 \\ P. GRIGIONI, ${ }^{d}$ G. CAMPOREALE, ${ }^{\text {e AND E. A. BERING }}{ }^{\mathrm{f}}$ \\ a Australian Antarctic Division, Australian Government, Kingston, Tasmania, Australia \\ ${ }^{\mathrm{b}}$ Arctic and Antarctic Research Institute, St. Petersburg, Russia \\ ${ }^{\mathrm{c}}$ The University of Texas at Dallas, Richardson, Texas \\ ${ }^{\mathrm{d}}$ Casaccia research Centre, ENEA, Rome, Italy \\ ${ }^{\mathrm{e}}$ Brindisi Research Centre, ENEA, Brindisi, Italy \\ ${ }^{\mathrm{f}}$ University of Houston, Houston, Texas \\ ${ }^{\mathrm{g}}$ University of Tasmania, Hobart, Tasmania, Australia
}

(Manuscript received 6 June 2016, in final form 28 November 2016)

\begin{abstract}
Atmospheric electric field measurements from the Concordia station on the Antarctic Plateau are compared with those from Vostok (560 km away) for the period of overlap (2009-11) and to Carnegie (1915-29) and extended Vostok (2006-11) measurements. The Antarctic data are sorted according to several sets of criteria for rejecting local variability to examine a local summer-noon influence on the measurements and to improve estimates of the global signal. The contribution of the solar wind influence is evaluated and removed from the Vostok and Concordia measurements. Simultaneous measurements yield days when the covariability of the electric field measurements at Concordia and Vostok exceeds $90 \%$, as well as intervals when significant local variability is apparent. Days of simultaneous changes in shape and mean level of the diurnal variation, as illustrated in a 5-day sequence, can be interpreted as due to changes in the relative upward current output of the electrified cloud generators predominating at low latitudes. Smaller average local meteorological influences are removed from the larger Vostok dataset, revealing changes in the shape of monthly average diurnal variations, which are similarly attributed to changes in predominantly low-latitude convection from month to month.
\end{abstract}

\section{Introduction}

Thunderstorms and strongly electrified clouds are the principal generators maintaining a time-varying, globally uniform, potential difference of $\sim 240 \mathrm{kV}$ (Markson 2007) between the ionosphere and Earth. The atmospheric electric circuit is completed by downward currents in regions away from strong convective-electrical meteorological activity. Galactic cosmic rays (GCR), modulated by the solar wind, are the major source of tropospheric ionization; with natural radioactivity contributing to ionization in the lowest few kilometers, over land. Broad global uniformity of the diurnal variation in the atmospheric circuit was established using "fair weather" electric field measurements from the oceanic cruises of the Carnegie, between 1915 and 1929 (Ault and Mauchly 1926; Torreson

\footnotetext{
Corresponding author e-mail: Brian Tinsley, tinsley@utdallas. edu
}

et al. 1946). The link between thunderstorm activity and the variability in the atmospheric circuit was confirmed by Whipple and Scrase (1936), from a hypothesis of Wilson (1921). The distribution of equatorial and midlatitude landmasses, and the formation of thunderstorms preferentially in the afternoon during local summer, is believed responsible for the average universal time (UT) variations (minimum $\sim 0400$ UT, maximum $\sim 1900$ UT) of the ionospheric potential and the resulting electric fields.

In regions away from the convective generators, a current density of $\sim 3 \mathrm{pA} \mathrm{m}^{-2}$ flows from the ionosphere to the ground (Bering et al. 1998) and a vertical electric field of $\sim 130 \mathrm{~V} \mathrm{~m}^{-1}$ (Carnegie average) can be measured near ground level. Local variations of these averages may occur as a result of surface altitude, conductivity, and space charge influences. The electric field relaxation time near Earth's surface is $\sim 15$ min (Rycroft et al. 2008).

The interaction of the solar wind and Earth's magnetic field imposes an additional potential difference in the polar 
regions, above $\sim 60^{\circ}$ magnetic latitude. These potentials map down magnetic field lines from the solar wind to the ionosphere in the northern and southern polar caps. The broadly dawn-to-dusk (horizontal), solar-wind-imposed ionospheric potential differences influence the vertical electric field at ground level (Park 1976). The electric field response near Earth's surface is essentially the same as a uniformly applied ionosphere-to-ground potential difference for horizontal ionospheric scale sizes greater than $\sim 200 \mathrm{~km}$ (Park 1976). The local influence of this external generator depends on magnetic coordinates unlike the influence of the convective meteorology generator (thunderstorms and strongly electrified clouds), which is globally uniform. Solar wind-imposed potential differences are maintained by the direct link of the magnetosphere to the ionosphere by the magnetic field. At about $\pm 75^{\circ}$ magnetic latitudes, where the average contribution to ionospheric potential of the external generator maximizes, it is still considerably less $(<20 \%)$ than that of the internal meteorological generator (Tinsley and Heelis 1993).

Empirical models have been developed relating solar wind-imposed potentials along satellite paths (measured by an integration of the electric field in the direction of motion) to solar wind parameters (Weimer 1996, 2001). It is thus possible to determine how the near-ground-level, vertical electric field responds diurnally and seasonally to solar-wind-imposed, horizontal variations in the local ionospheric potential difference in the polar regions and adjust the measurements to remove the solar wind influence (Corney et al. 2003; Burns et al. 2012).

Greenhouse warming of the troposphere is expected to lead to enhanced thunderstorm activity [see review by Williams (2005)]. Both the mean state and variability in climate models are sensitive to the parameterization of cumulus convection (IPCC Assessment Report 5, Clouds and Aerosols; Boucher et al. 2013). Additionally, natural and anthropogenic aerosols influence both the atmospheric circuit (Zhou and Tinsley 2010) and weather and climate (Boucher et al. 2013). As meteorological electrical activity is the dominant driver of the atmospheric circuit and as the solar wind modulates the GCR flux which influences atmospheric conductivity, the current flow is responsive to both solar variability and meteorological electrical activity. It has been hypothesized that the atmospheric circuit may provide means via which solar variability could influence weather and climate (e.g., Markson 1978; Tinsley 2008, 2012). Electric field measurements have been used to link a solar wind influence on the surface pressure in polar and nearby latitudes to the atmospheric circuit (Mansurov et al. 1974; Burns et al. 2008; Lam et al. 2013).

Monitoring the atmospheric circuit offers the possibility of measuring parameters that are not only sensitive to climate, but that may be an input to climate. However, maintaining accurate measurements with high time resolution has proved difficult. The globally uniform component of the atmospheric circuit is the ionosphere-Earth potential difference equatorward of the polar regions. Reliable but infrequent airplane and balloon height-integrated measurements of this convective cloud-maintained ionospheric potential have been reviewed by Markson (2007). Alternatively, air-Earth current density can be measured (Reddell et al. 2004). These values apply to the groundionosphere column in which the measurement is made, but can prove difficult because they are sensitive to very small leakage currents on equipment surfaces. Near ground level, electric field measurements are technically simple and relatively common but can be affected by local air conductivity changes and the variability of space charge.

Despite the difficulties with surface-level electric field measurements, the often-used reference for diurnal variations in the global atmospheric circuit remains that derived from a limited number of selected days (likely 141 days; discussed later) of electric field measurements made during the cruises of the Carnegie almost $100 \mathrm{yr}$ ago, the "classic Carnegie curve" [Table XIX, p. 647 of Israel (1973), Vol. II]. The remnant preference for oceanic measurements is because even without any turbulence due to wind, any convective activity at a site moves space charge around, which can produce largeamplitude fluctuating electric fields. Without convection or turbulence the space charge produced by the electrode effect and vertical conductivity gradients can remain stably stratified and does not perturb the relative diurnal variation of the electric field. The amount of diurnal variation in convection at sea is much less than on land-hence, the value of the Carnegie data. The Antarctic Plateau near-surface air is stably stratified except for an interval of convection around local noon in summer (Argentini et al. 2014). It is almost entirely free of moisture, radon, dust, and aerosol from sea salt spray and anthropogenic sources. There are no diurnalseasonal biological influences on aerosols. Average diurnal variations of meteorological parameters are significantly reduced across the portion of the year when the sun remains below the horizon; and average temperature, wind speed, and pressure influences on electric field measurements at Vostok have been determined using a multivariate analysis of responses to the solar wind-imposed potential difference (Burns et al. 2012).

In this paper we compare Antarctic Plateau electric field measurements from Vostok $\left[78.5^{\circ} \mathrm{S}, 107^{\circ} \mathrm{E} ; 83.6^{\circ} \mathrm{S}\right.$ mag. (corrected geomagnetic coordinates, available from the National Space Science Data Center OMNIWeb database); 2006-11] and Concordia $\left(75.1^{\circ} \mathrm{S}, 123^{\circ} \mathrm{E} ; 89.0^{\circ} \mathrm{S}\right.$ mag.; 2009-11; 560-km separation). We quantify the 
day-to-day and seasonal consistency and variability of simultaneous electric field $\left(E_{z}\right)$ measurements at two Antarctic Plateau stations collected over 3 yr (200911). Dual-site observations lead to a more appropriate $E_{z}$ data selection across the austral summer boundary layer convection interval and yield improved estimates of variations in the atmospheric circuit.

Three-monthly Vostok and Concordia diurnal averages are compared with the originally reported $\mathrm{Car}$ negie seasonal variations (Ault and Mauchly 1926; Torreson et al. 1946) and the advantages of the modern datasets with respect to the classic Carnegie curve (Israel 1973) are discussed. Monthly diurnal estimates of the global atmospheric circuit derived from the Vostok 2006-11 dataset are corrected for the average meteorological influences determined by Burns et al. (2012) and show intervals of rapid month-to-month change and intervals of relative month-to-month stability across the year.

\section{Instrumentation, data, and the Weimer models}

An Australian Antarctic Division (AAD)-manufactured rotating-dipole Electric Field Mill (EFM) Mark 3 was installed at the Russian Vostok station from January 2006. The major differences from the Vostok EFM used in the 1998-2001 era (Burns et al. 2005) are optical signal coupling from the rotating dipole, which improves the stability of the instrument, and a larger height of $\sim 3 \mathrm{~m}$ above the snow. A similar instrument was deployed at the French-Italian station Concordia between January 2009 and December 2011. The Vostok 2006-11 and Concordia 2009-11 electric field data analyzed in this paper are available online from the Australian Antarctic Data Centre (https://data.aad.gov.au/ metadata/records/ASAC_974_2; https://data.aad.gov.au/ metadata/records/ASAC_974_Concordia).

The new instrumentation was calibrated by stepping voltages between +5 and $-5 \mathrm{kV}$ through a wire above the EFM at Vostok. The electric field values $\left(\mathrm{V} \mathrm{m}^{-1}\right)$ used herein are absolute values. These differ from the earlier-era Vostok values, which were only calibrated relative to a Faraday-shielded box containing parallel plates placed over the rotating dipole to which a stepped range of voltages is applied and are described as "relative values." The Faraday-shielded box was used for intercalibration of the Vostok and Concordia EFMs. Electric field measurements are collected at 10-s resolution, converted to 1-min and then 20-min averages.

Local meteorology, principally associated with high wind speeds, limits the times when electric field measurements at Antarctic Plateau sites can be utilized to investigate the global atmospheric circuit. Data selection is determined on the basis of the electric field values alone. This approach was devised to account for the varying initiating wind speeds, likely dependent on the speed required to lift snow and ice particles into the air under varying ice surface conditions, for which a rapid increase in the electric field values is observed (Burns et al. 1995). An initial rejection of the minuteaveraged data is made on the basis of the fields exceeding $300 \mathrm{~V} \mathrm{~m}^{-1}$ at Vostok, or $333 \mathrm{~V} \mathrm{~m}^{-1}$ for the higher field values at Concordia, over widened time intervals of $2 \mathrm{~h}$ from the times of the fields exceeding these thresholds. This extended time interval is a conservative allowance for the influence of lifting snow and ice before and after the cut-off electric field value is reached. Rapid variations below these thresholds are also rejected, at two levels of severity, on the basis of jumps in the field within a 5-min interval. Data within $30 \mathrm{~min}$ of a jump of $30 \mathrm{~V} \mathrm{~m}^{-1}$ (within $5 \mathrm{~min}$ ) at Vostok or $33 \mathrm{~V} \mathrm{~m}^{-1}$ at Concordia are rejected and are designated "strong variability rejection" (svr). These svr selection criteria are similar to those used for the 1998-2001 Vostok electric field measurements (Burns et al. 2005, 2012). When specifically for Vostok the designation of the data remaining is $\operatorname{Vos} E_{z}^{s}$ and for Concordia it is Con $E_{z}^{s}$. Less severe rejection criteria are helpful for analyzing the austral summer variability around local noon, and the designations are "medium variability rejection" (mvr) and $\operatorname{Vos} E_{z}^{m}$ and Con $E_{z}^{m}$. For mvr the minute-averaged values are rejected within $10 \mathrm{~min}$ of jumps (within $5 \mathrm{~min}$ ) of larger than $50 \mathrm{~V} \mathrm{~m}^{-1}$ for Vostok and $57 \mathrm{~V} \mathrm{~m}^{-1}$ at Concordia. All the data remaining after the initial rejection based on fields exceeding $300 \mathrm{~V} \mathrm{~m}^{-1}$ at Vostok, or $333 \mathrm{~V} \mathrm{~m}^{-1}$ at Concordia are designated "no variability rejection" (nvr) and Vos $E_{z}^{n}$ and Con $E_{z}^{n}$. Rapid-variability rejection criteria are generally appropriate because rapid variations in electric field measurements likely result from local variations rather than ionospheric influences, owing to the $\sim 15$-min relaxation time of the atmospheric circuit (Rycroft et al. 2008).

Analysis of the earlier-era Vostok data found that the 5-min-difference rejection criteria dramatically reduced the amount of data selected in the austral summer around local noon ( $\sim 0450$ UT; Burns et al. 2012). A local convection process was postulated as responsible for this rapid $E_{z}$ variability and associated enhanced data rejection. Herein, separate data selections using a relaxation of the 5-min-difference rejection criterion are used to investigate the influence of this criterion. Figure 1 shows the influence of these three different data selections on the Vostok monthly diurnal averages, most obviously in the January and December curves. For the three data selections detailed above, the annual 

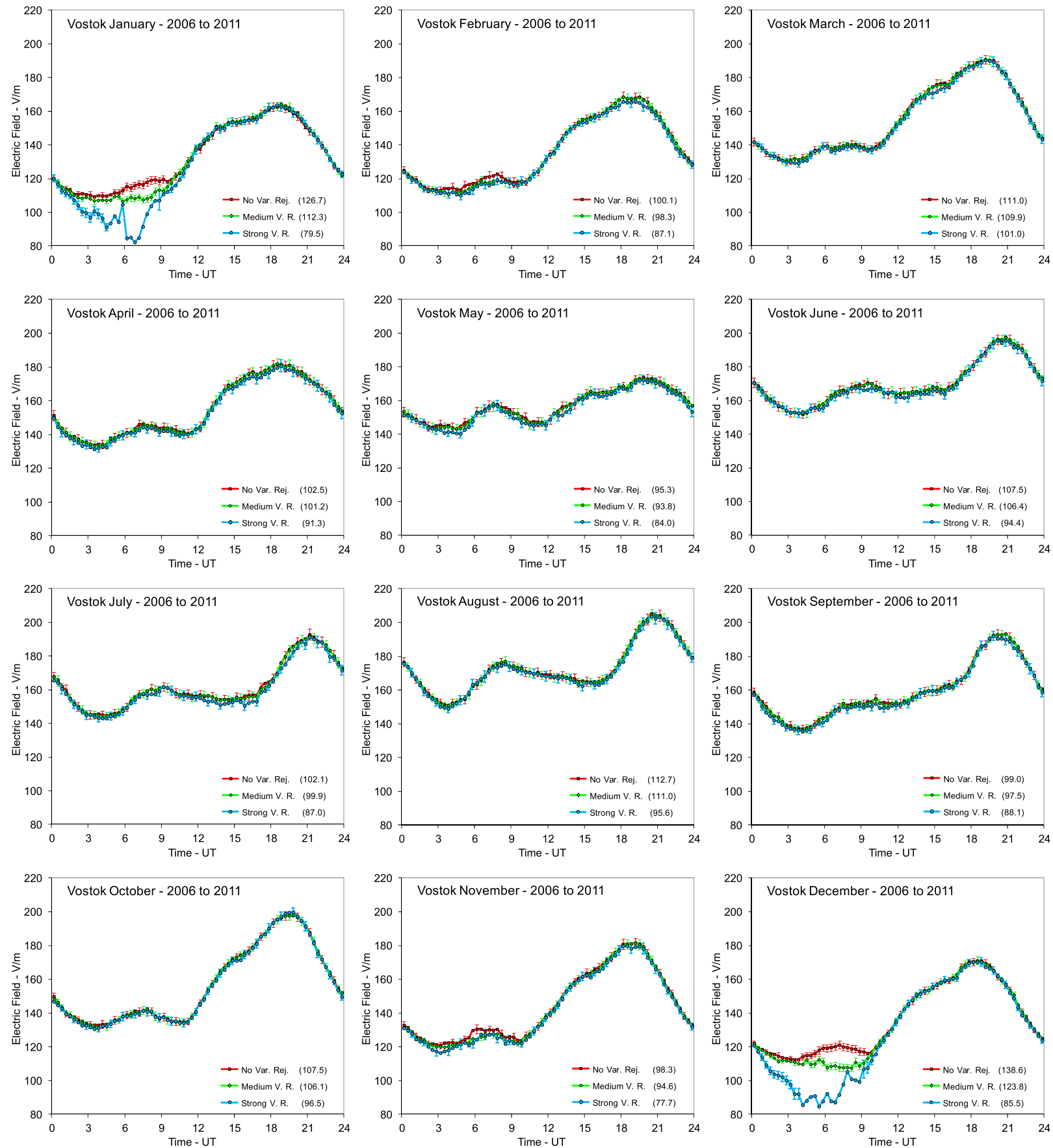

FIG. 1. Monthly diurnal Vostok electric field averages for three data selections described in the text, after correction for the solar windimposed potential difference. Local solar noon is $\sim 0450 \mathrm{UT}$. Errors are plus and minus one error in the mean but are not shown for sample size less than 10. Equivalent days of contributing data are indicated in parentheses.

coverage for Vostok (Concordia) are 50\% (52\%), 59\% $(66 \%)$, and $61 \%(70 \%)$, respectively. Annual percentages of time for which measurements at least one of the two stations meet the data selection criteria are $78 \%$, $89 \%$, and $91 \%$, respectively.
Temperature, pressure, wind speed, and wind direction values are available with 1-min resolution from automatic weather stations (AWS) at both Vostok and Concordia. These meteorological data are available on request [please see http://www.aari.ru/gosros/main.php 
(Vostok); www.climantartide.it (Concordia)]. The Concordia AWS has both heated and nonheated anemometers and wind direction sensors. The Concordia wind speed values are selected on the basis of which anemometer recorded the larger average over each 20-min interval. The heated anemometer generally gave larger values at lower wind speeds. The heated direction sensor was less likely to exhibit "stickiness," but an intermittent fault in the most significant binary digit was found and avoided in data selection.

The Weimer (2001) model is used to calculate the solar wind-imposed contribution to the ionosphere-to-ground potential difference above Vostok and Concordia. This model calculates the solar wind-imposed potential differences from geocentric solar magnetospheric (GSM) interplanetary magnetic field (IMF) $B_{z}$ and $B_{y}$ components, solar wind velocity, the dipole tilt angle (the angle between the magnetic centered-dipole axis and the GSM $z$ axis), the solar wind density, and an optional auroral activity index (AL). The indices AL and AU broadly measure the intensity of the morning and evening auroral electrojets, respectively, via the magnetic disturbance in nanoteslas (nT), determined from a selection of auroral stations. Increased auroral activity yields more-negative AL and more-positive AU. The index AE is a measure of general auroral activity, calculated as AU minus AL (World Data Centre for Geomagnetism, Kyoto; http://wdc.kugi.kyoto-u.ac.jp/aedir/ae2/ onAEindex.html). Solar wind data shifted to Earth's bow shock nose (referred to herein as the noon magnetopause) and auroral activity indices were obtained via the National Space Science Data Center OMNIWeb database.

The monthly diurnal averages for Vostok electric field measurements presented in Fig. 1 show each of the three data selections. These plots show significant separation of the January and December curves around local noon ( $\sim 0450$ UT) dependent on the criterion used to reject rapidly varying data. In the appendix, the solar wind-imposed potential (SWIP) above each station calculated using the Weimer (2001) model is used to determine the appropriate correction for this influence on the Vostok and Concordia $E_{z}$ measurements. Burns et al. (2012) have shown that the diurnal and seasonal Vostok electric field sensitivity $\left(\mathrm{V} \mathrm{m}^{-1} \mathrm{kV}^{-1}\right)$ to SWIP is uniform within the uncertainty limits. The SWIP correction has been applied to the Vostok monthly averages in Fig. 1 and to the $E_{z}$ measurements for both stations hereafter, unless otherwise noted.

In the appendix, linear regressions of the SWIP with the three $E_{z}$ datasets at each station are used to determine the statistical significance of each svr, mvr, and nvr dataset response to the SWIP variations. The linear regressions of all datasets are strongly statistically significant. For both stations, $t$ statistics are larger for the svr datasets, followed by the mvr and then the nvr datasets. We infer that local variations contribute more often to the mvr and nvr datasets, which are less restrictive than the svr datasets, consistent with a groundlevel atmospheric circuit response time of $\sim 15 \mathrm{~min}$.

Also in the appendix, we investigate the differences between the diurnal average of the svr and nvr datasets across the March-October (MAMJJASO) interval when no local-noon preference for separation of the respective datasets is apparent (see Fig. 1). The diurnal mean of the MAMJJASO Vostok nvr data is $13 \mathrm{Vm}^{-1}$ greater than the mean of the svr data. When the svr and nvr MAMJJASO diurnal averages are both plotted as percentage of the diurnal mean, they are well matched. Similar results are obtained for Concordia, with the svr and nvr means differing by $12 \mathrm{~V} \mathrm{~m}^{-1}$.

\section{Insights and comparisons from Vostok and Concordia $E_{z}$ measurements}

Concordia provides an example that the svr data selection is better than mvr and nvr data selections for rejecting a local anthropogenic influence on the measurements. Figure 2 a shows the number of samples when the wind comes from particular directions, separately for the "climate" (all wind direction measurements across 2009-11) and for the three data selections. The wind comes mainly from the south. The Concordia powerhouse is located $\sim 900 \mathrm{~m}$ in a direction $104^{\circ}$ east from the EFM. Figure $2 b$ shows strong rejection of all but a few percent of the data from the direction of the powerhouse for the svr selection. The parameter plotted is 100 times the ratio of the number of samples accepted to the number of samples of the climatological azimuthal wind, for each azimuth bin. The powerhouse is a local source of aerosol emissions that may influence electric field measurements by altering the atmospheric conductivity or space charge.

Insights into the anomalous behavior around local noon of the December-January diurnal averages at Vostok and Concordia, as shown in Fig. 3a can be gleaned from Fig. $3 b$, which shows the diurnal variations in the number of measurements that respectively pass the three data selections. Vostok and Concordia are separated by $560 \mathrm{~km}$; local noon occurs at $\sim 0450$ and $\sim 0350$ UT respectively. Almost no measurements pass the most-restrictive svr data selections around local noon. A displacement of about an hour in the reduction and recovery of the number of measurements at Vostok and Concordia is apparent, with Concordia leading (Fig. 3b). A similar displacement is apparent in the respective diurnal averages (Fig. 3a), with lower average $E_{z}$ values associated with a reduction in the number of measurements passing the respective selection criteria. Similar 


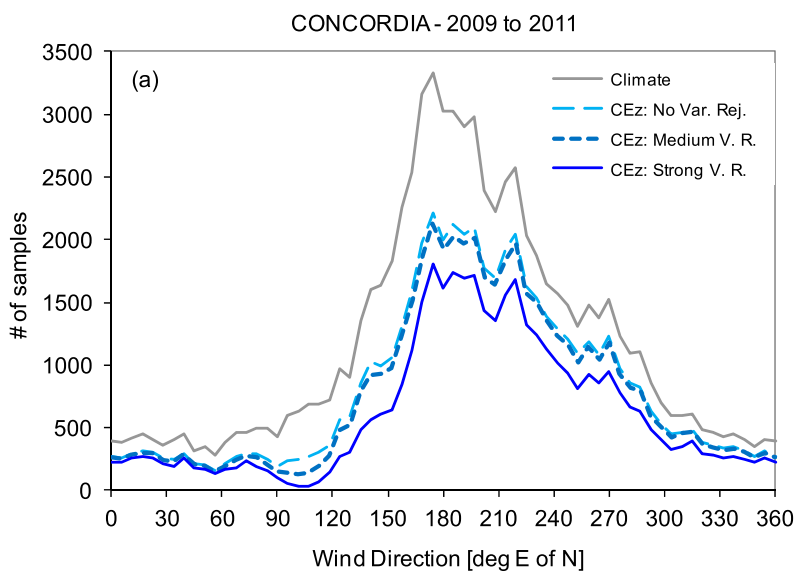

CONCORDIA - 2009 to 2011

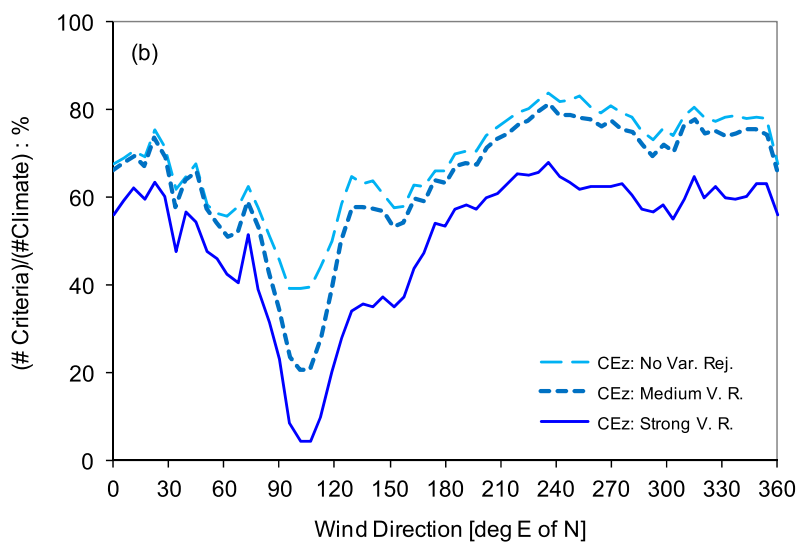

FIG. 2. (a) The number of wind direction samples, separately for Concordia climate (2009-11) and three indicated data selections. (b) The ratio (number of samples for each criteria):(number of samples for climate) expressed as a percentage. The Concordia powerhouse is in the direction $104^{\circ}$ east of north.

time displacements of Vostok and Concordia measurements and diurnal averages can be discerned for the mvr data. These offsets confirm a local time influence on the summer-noon electric field variability at both sites.

Casasanta et al. (2014) measure and model the development of a summer convective atmospheric boundary layer at Concordia. The convection turbulence develops between 0600 and 1600 local time (2200$0800 \mathrm{UT}$ ), corresponding with the interval of rapid $E_{z}$ variations. Outside this summer, local-noon interval the atmospheric boundary layer at Concordia is stable (Argentini et al. 2014). The rapid $E_{z}$ variability is likely associated with turbulence in the convective boundary layer. Figure 3 confirms that the variability rejection criteria preferentially favor lower $E_{z}$ values and bias the averages. The nvr Vostok and Concordia diurnal averages show a better match and smoother variations around local noon. Thus, despite the better statistical responses to the solar wind-imposed influences using
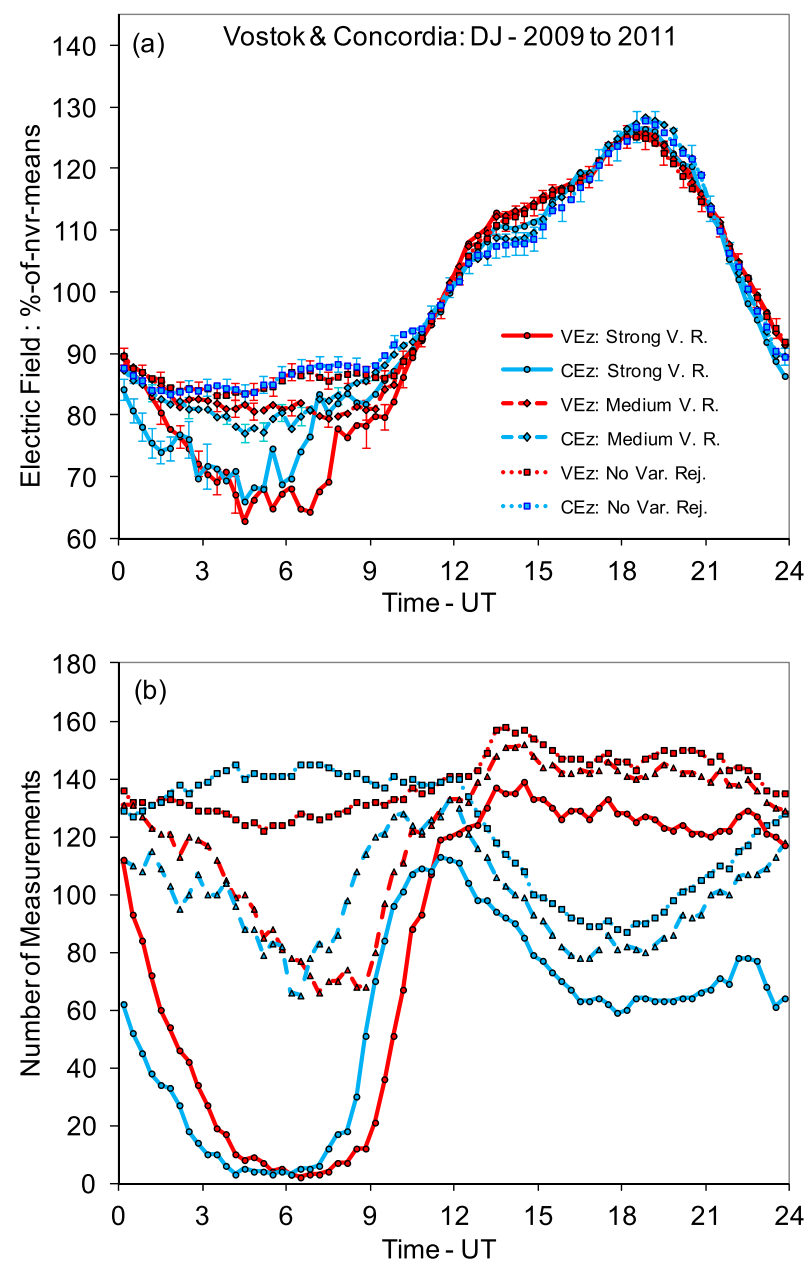

FIG. 3. (a) Vostok and Concordia December-January (2009-11)average diurnal curves for the data selections indicated. Errors are plus and minus one error in the mean but are not shown for sample size less than 10. (b) Diurnal variations of the number of measurements.

data selections with rapid-variability rejections, the best estimates of the average diurnal curves for the globally uniform component of the ionosphere-toground potential difference at Vostok and Concordia for December, January, and possibly for November are given by the nvr datasets.

The December-January reduction in samples at Concordia centered on $\sim 1800$ UT is dominantly due to exceeding the criterion for the rejection of large field excursions. Recently installed automated lidar measurements at Concordia show a December-January diurnal dominance of reduced horizontal, ground-level visibility between 1600 and 2200 UT. Radiative cooling following the cessation of the summer convectiveturbulence interval results in a diurnal minimum in both temperature and wind speed around this time. This supports the formation of fog over the alternative of 
TABLE 1. The correlation coefficient squared $\left(R^{2}\right)$ and associated information for simultaneous 20-min averages for Vostok and Concordia data selections indicated. Percentage data and $R^{2}$ differences are listed with respect to svr datasets (ref 1-ref 4) for each 3-month interval.

\begin{tabular}{|c|c|c|c|c|c|}
\hline Seasons and datasets & $R^{2}$ & No. of samples & Days & Amount of data included (\%) & $R^{2}$ diff \\
\hline \multicolumn{6}{|l|}{ NDJ } \\
\hline Vos: svr and Con: svr & 0.761 & 4196 & 58.3 & Ref 1 & - \\
\hline Vos: mvr and Con: mvr & 0.688 & 7312 & 101.6 & +74.3 & -0.073 \\
\hline Vos: nvr and Con: nvr & 0.570 & 9306 & 129.3 & +121.8 & -0.191 \\
\hline \multicolumn{6}{|l|}{ FMA } \\
\hline Vos: svr and Con: svr & 0.615 & 6756 & 93.8 & Ref 2 & - \\
\hline Vos: mvr and Con: mvr & 0.587 & 8508 & 118.2 & +25.9 & -0.029 \\
\hline Vos: nvr and Con: nvr & 0.544 & 8940 & 124.2 & +32.3 & -0.071 \\
\hline \multicolumn{6}{|l|}{ MJJ } \\
\hline Vos: svr and Con: svr & 0.580 & 6294 & 87.4 & $\operatorname{Ref} 3$ & - \\
\hline Vos: mvr and Con: mvr & 0.565 & 8374 & 116.3 & +33.0 & -0.015 \\
\hline Vos: nvr and Con: nvr & 0.554 & 8700 & 120.8 & +38.2 & -0.026 \\
\hline \multicolumn{6}{|l|}{ ASO } \\
\hline Vos: svr and Con: svr & 0.5623 & 6261 & 87.0 & $\operatorname{Ref} 4$ & - \\
\hline Vos: mvr and Con: mvr & 0.5553 & 8385 & 116.5 & +33.9 & -0.007 \\
\hline Vos: nvr and Con: nvr & 0.5351 & 8762 & 121.7 & +40.0 & -0.027 \\
\hline
\end{tabular}

wind-lifted snow. Unlike the local-noon convectiveturbulent influence on $E_{z}$, which occurs at both sites, the near-midnight reduction in selected $E_{z}$ measurements at Concordia is not apparent at the windier Vostok site.

While diurnally averaged electric field values have been used to define the atmospheric circuit, local variations in a range of atmospheric factors can influence individual measurements. The influence on electric field measurements of independent local variations can be determined by comparison of simultaneous measurements from each site. The square of the correlation coefficient ( $R$ squared) of simultaneous Vostok and Concordia 20-min averages corrected for the local solar wind influence for 3-monthly intervals, for each data selection, are listed in Table 1 . The $R$-squared value represents the fraction of variation common to both variables. For all seasons, the svr datasets yield higher $R$-squared values providing an independent confirmation that they are better at rejecting local variations and are more representative of a global signal.

Scatterplots of the simultaneous Vostok and Concordia averages for the strictest data selections, for each of four 3-monthly intervals, are shown in Fig. 4. The full lines are the best fits, using Vostok $E_{z}$ as the independent variable, to minimize Concordia $E_{z}$ least squares deviations. The dashed lines are the best fits, using Concordia $E_{z}$ as the independent variable (now the vertical axis on each plot), to minimize Vostok least squares deviations. These lines yield the same $R$-squared values (listed on plots). Differences from these lines provide an estimate of local influences on the individual Vostok and Concordia measurements, respectively. The average standard deviations about these lines are $11.9 \%$ and $12.5 \%$, expressed as a percentage of the mean $E_{z}$. The small difference suggests conductivity and space charge variability may be slightly less at Vostok than at Concordia, which is located on a broad dome and has lower average wind speeds.

Local influences on $E_{z}$ measurements have generally limited their usefulness for atmospheric circuit research to diurnal averages. Individual UT-day, twin-site comparisons with high $R$-squared values provide some confidence of the shape of the diurnal variation in the atmospheric circuit on individual days. A histogram of the daily $R$-squared values of the 18 Vostok and Concordia days with complete svr coverage is plotted in Fig. 5 as the black line. The mean $R$-squared value is 0.83 . For the nvr data selections there are 124 complete days. The mean is 0.72 . A histogram of these 124 values, also included in Fig. 5 as the gray line, shows a peak in the $0.85-0.90$ interval but a tail of low values. Low daily $R$-squared values indicate the measurements for at least one site are variably influenced by local factors.

Figure 6 shows simultaneous measurements across 5 consecutive days at Vostok and Concordia. Similarities and differences between the Vostok and Concordia electric field measurements are apparent. The top plot shows raw 1- and 20-min averages from both sites. Below that, raw and corrected-for-solar-wind-influence (Corr. SWI) 20-min averages are plotted. Temperature, wind speed, and auroral indices complete the stacked plots. The time axis lists hours after 0000 UT 6 March 2009. The $R$-squared value for the middle 3 days is 0.917 . These 5 days exhibit an upward trend in $E_{z}$ and a downward trend in temperature, at both sites; however, the magnitude of the trend in $E_{z}$ is much 

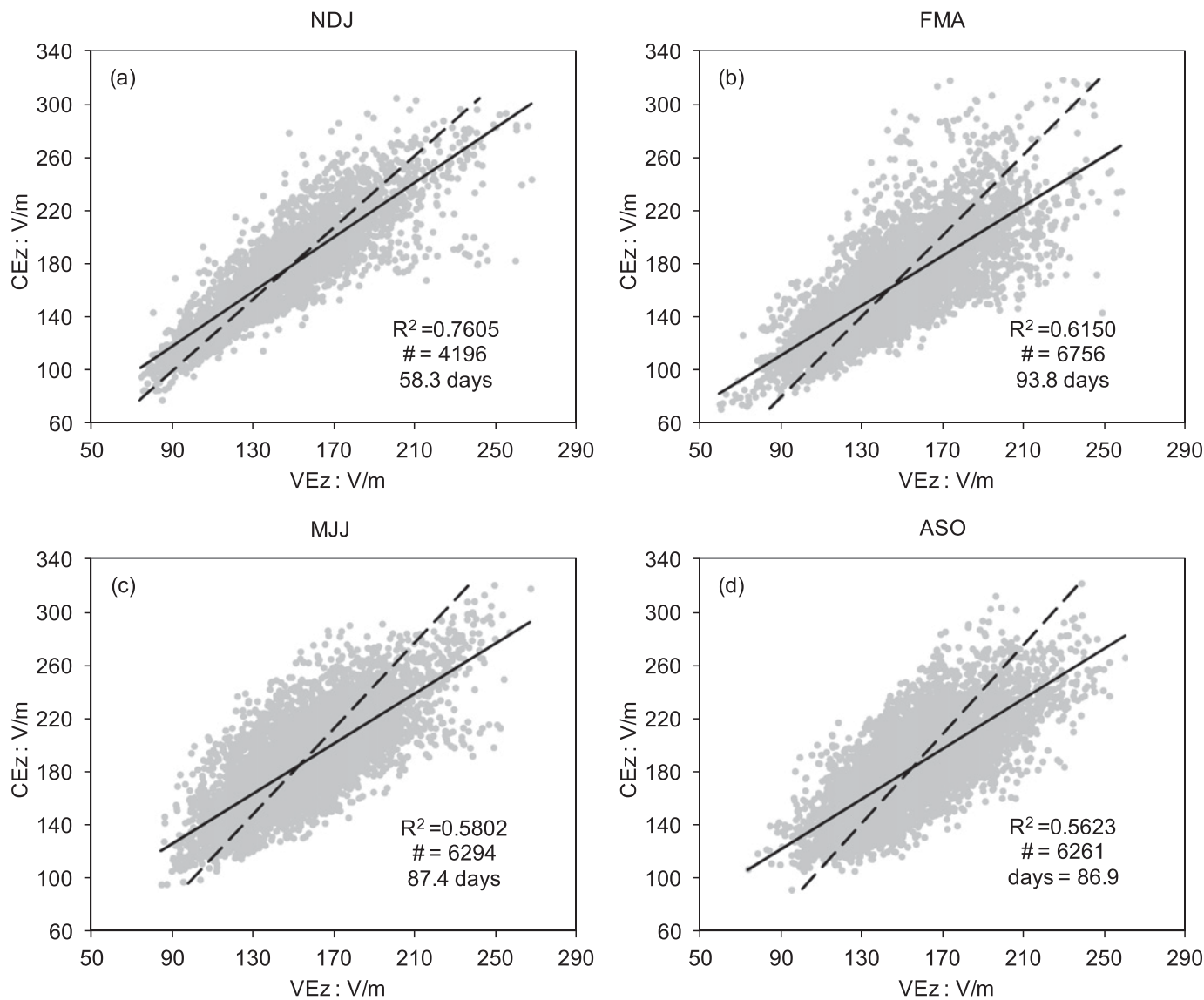

FIG. 4. Vostok and Concordia 3-monthly comparison plots for the strictest (svr) data selections. On each plot are tabulated the square of the correlation coefficient $\left(R^{2}\right)$ and the amount of data. The full lines are the best-fit lines, using Vostok $E_{z}$ as the independent variable, to minimize Concordia $E_{z}$ least squares deviations. The dashed lines are the best fits, using Concordia $E_{z}$ as the independent variable (now the vertical axis in each panel), to minimize Vostok least squares deviations.

greater than can be accounted for by the inverse association of temperature with Vostok $E_{z}$ that was reported by Burns et al. (2012). A plausible interpretation would be changes on the synoptic time scale in the global electrified cloud and thunderstorm generators, which occur predominantly at low latitudes. It is also apparent that the shape of the diurnal variations can change from day to day, in a manner broadly consistent between the sites. Local meteorological influences and variations between the sites are also apparent. Comparing the Vostok raw 1-min electric field values with the wind speed for the earliest day show how small variations in average wind speed can dramatically alter the electric field. This is a common $E_{z}$ observation in Antarctica and is likely due to lifted snow modifying the local space charge or conductivity. The onset and cutoff speeds for wind-lifted snow are variable, even within the same day (Burns et al. 1995). Near the commencement of the fifth day (around $72 \mathrm{~h}$ ) there is a separation of the Vostok and
Concordia electric field measurements. However, by the later portion of the day when the Concordia wind speed is low $(>87 \mathrm{~h})$, the electric field measurements are broadly similar. For the major portion of the day some difference in the ratio of column to near-ground-level conductivity or space charge has resulted in a difference between the $E_{z}$ measurements at the sites, but this cannot be directly attributed to the later occurrence of low wind speeds at Concordia.

Auroral activity indices AL, AU, and AE, described in section 2, are shown in the lowest of the stacked plots. As quantified in the appendix, including the Weimer (2001) option of an AL auroral activity index did not improve the statistical association of the solar windimposed potential difference with the electric field measured at the high-magnetic-latitude stations of Vostok or Concordia. However, this does not mean there are no auroral substorm influences on the electric field measurements. An example of auroral influence is 


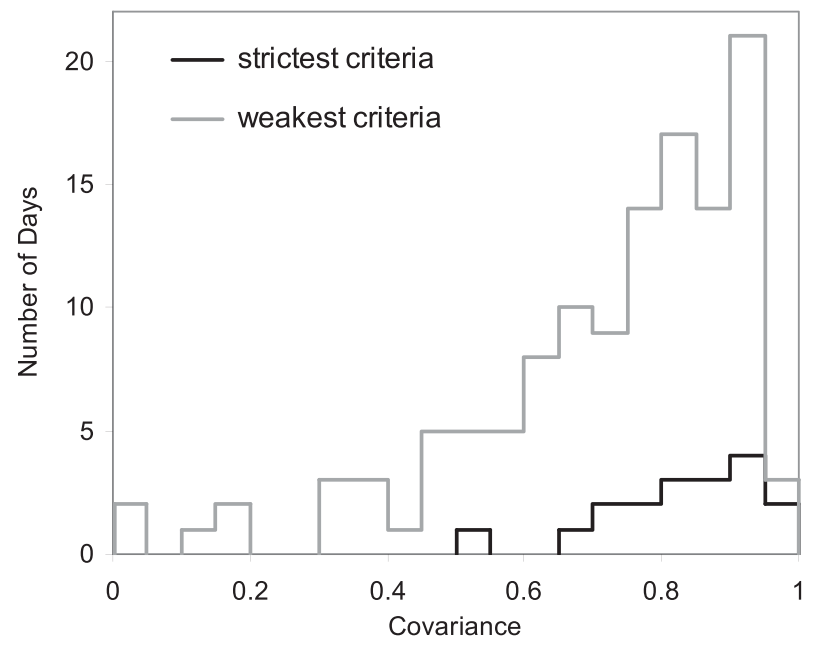

FIG. 5. Histograms of $R^{2}$ for individual complete days, for the strongest (black line: Vostok svr and Concordia svr) and weakest (gray line: Vostok nvr and Concordia nvr) variation rejection data selections.

apparent around $60 \mathrm{~h}$, in Fig. 6. Figure 7 shows a lead-lag regression coefficient plot of Vostok $E_{z}$ and AL and of Concordia $E_{z}$ and AL for the event noted. For the 6-h interval compared, the regression coefficient peaks at greater than 0.65 for both stations, at an $E_{z}$ lag of 0 or $20 \mathrm{~min}$. Westward auroral electrojet activity dominates this event (Fig. 6, bottom), and AL yields slightly larger magnitude regression coefficients than AE.

A difficulty with associating auroral activity with electric field is that the phase and magnitude of the electric field response depends on the magnetic local time and location of the site with respect to the auroral substorm and auroral oval (Kleimenova et al. 2011). Average electric field responses under varying conditions are required. The Weimer (2001) model with and without AL option may provide the necessary auroral substorm context for future studies.

\section{Seasonal comparisons with the classic Carnegie curve}

Ault and Mauchly (1926) and Torreson et al. (1946) examine Carnegie seasonal variability in 3-monthly intervals: November-January (NDJ), February-April (FMA), May-July (MJJ), and August-October (ASO). Ault and Mauchly (1926) list Fourier components (offset, 24-, 12-, 8-, and 6-hourly periodicities; their Table 80, p. 397) derived for these 3-monthly seasonal intervals from a total of 59 days of electric field measurements selected from cruises IV,V, and VI. Torreson et al. (1946, p. 136) list similarly derived seasonal Fourier components from 82 days selected from cruise VII. Both
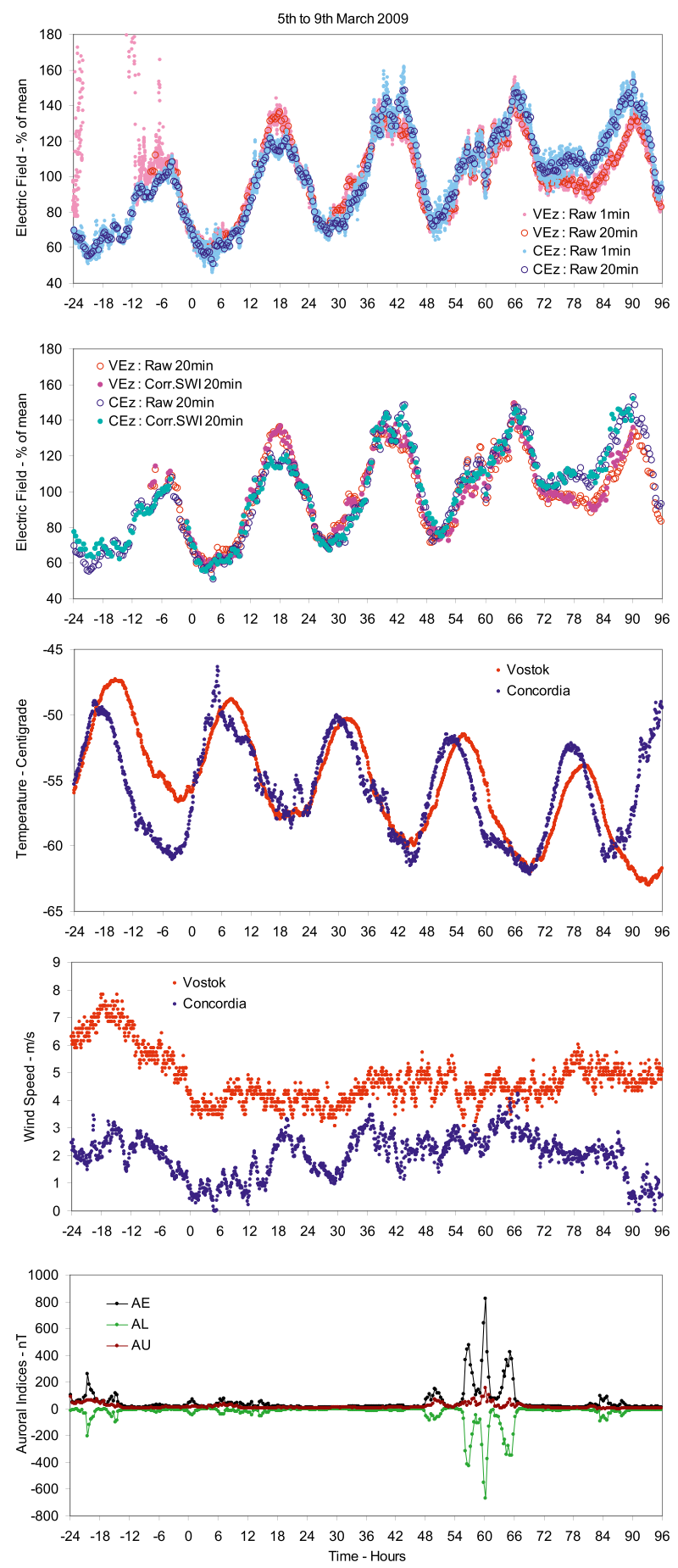

FIG. 6. Stacked plots of electric field measurements, temperatures, and wind speeds at Vostok and Concordia, and AL, AU, and AE auroral indices for 5 consecutive days in March 2009.

publications list the hourly averaged electric field values for each individual day, thus allowing calculation of seasonal errors in the mean from the combined dataset of 141 days. 


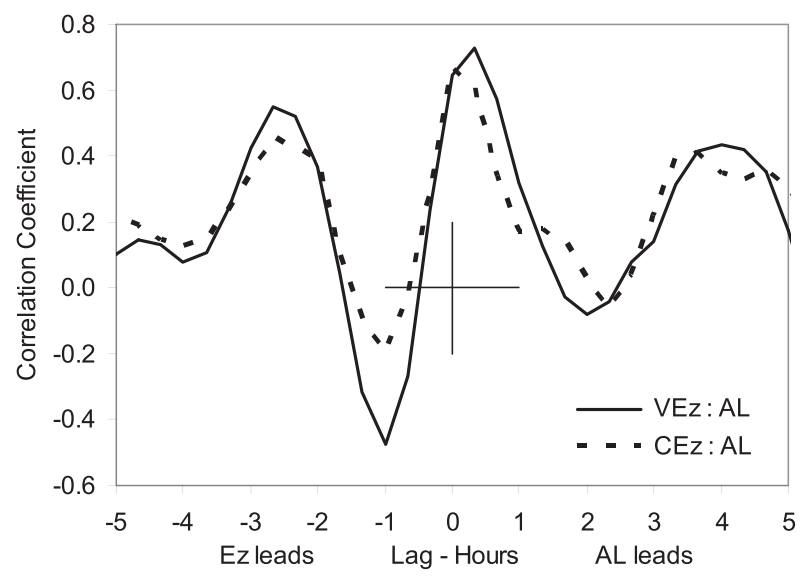

FIG. 7. Variations in regression coefficients between electric field measurements at Vostok and Concordia and the auroral activity index AL for the indicated timing offsets for a 6-h interval on 8 Mar 2009.

The diurnal mean of the combined 141 days matches the $129 \mathrm{~V} \mathrm{~m}^{-1}$ diurnal mean of the classic Carnegie curve [CCC; Table XIX, p. 647 of Israel (1973), Vol. 2]. However, the CCC comprises values listed "on the UT hour," while the original Carnegie measurements (Ault and Mauchly 1926; Torreson et al. 1946) are centered "on the UT half hour." We infer the CCC likely comprises Fourier-reconstituted, on-the-hour values derived from on-the-half-hour measurements. To confirm any statistical significant differences between diurnal averages, errors in the means are required. Our Carnegie data selection allows a statistical comparison with seasonal averages selected by the original researchers.

Figure 8 compares the 3-monthly diurnal averages of the Vostok, Concordia, and Carnegie data. Errors in the means (plus and minus one standard error) are shown and the amount of data contributing to each seasonal average is listed as equivalent days in the legends. The Vostok and Concordia standard errors include a contribution from the SWIP subtraction (square root of the sum of squares), but this is small compared to the sampling errors. The Vostok and Concordia NDJ diurnal averages are derived from the nvr data selections, as the best estimate for these austral summer months. Svr data, which are less influenced by local variations, are used for the other 3-monthly diurnal averages. Broadly, the Carnegie seasonal averages are similar to the modern datasets and show the seasonal shift in the diurnal maximum between NDJ ( 1800 UT) and MJJ ( 2000 UT) generally attributed to the longitudinal displacement of South America with respect to North America and the summertime dominance of meteorological convective-electrical activity.
All three datasets show broadly similar seasonal variations in the three global chimneys of convective meteorological activity at the UT corresponding to late afternoon and evening local times [Australia-Asia ( $\sim 0800$ UT), Africa-Europe $(\sim 1500$ UT), and North and South America ( 1900 UT)]; however, the Carnegie FMA and MJJ diurnal averages show stronger Africa-Europe signals than the modern datasets. But these differences are not statistically significant as they are always less than twice the errors in quadrature. However the shift in the Carnegie diurnal maximum between NDJ and MJJ, noted earlier, is reflected in statistically significant differences of the UT hours flanking the diurnal maxima (1230-1530 and 2230 0030 UT). Given that the relatively sparse Carnegie data yield a statistically significant difference between NDJ and MJJ, the extreme seasonal sampling difference (52 days in NDJ compared with 19 days for MJJ) suggests care should be taken when interpreting the $\mathrm{CCC}$ average of the individual days as an annually representative diurnal variation. The accuracy of averaged data is mathematically limited by the error in the mean. Figure 8 demonstrates that the modern data substantially reduces the errors in the mean while it is statistically consistent with the Carnegie data.

\section{Vostok monthly diurnal averages and month-to-month variability}

Figure 9 shows the Vostok monthly diurnal averages corrected for SWIP and adjusted for the average local meteorological influences as per Burns et al. (2012). Also shown in each panel are the prior and following monthly curves adjusted to the average temperature and percentage of the mean of the central month. The relative intensities of the global convective chimneys change most rapidly across the months August-October and April-June and are most stable across the months extending from the solstices: December-February and June-August.

The standard errors shown (plus and minus one standard error) are calculated as the square root of the sum of the squares of the contributing uncertainties. Larger errors are apparent in the adjacent months that required larger adjustments for temperature differences relative to that of the central month. Extracting the annual variation in the mean monthly electric field magnitudes remains a difficulty, in view of the very large temperature changes (from less than $-70^{\circ} \mathrm{C}$ to more than $-40^{\circ} \mathrm{C}$ ) between $\mathrm{SH}$ winter and summer. These may be associated with large conductivity changes that we are unable to quantify (e.g., due to changes in air ion mobility with enhanced clustering at the extremely low temperatures). 

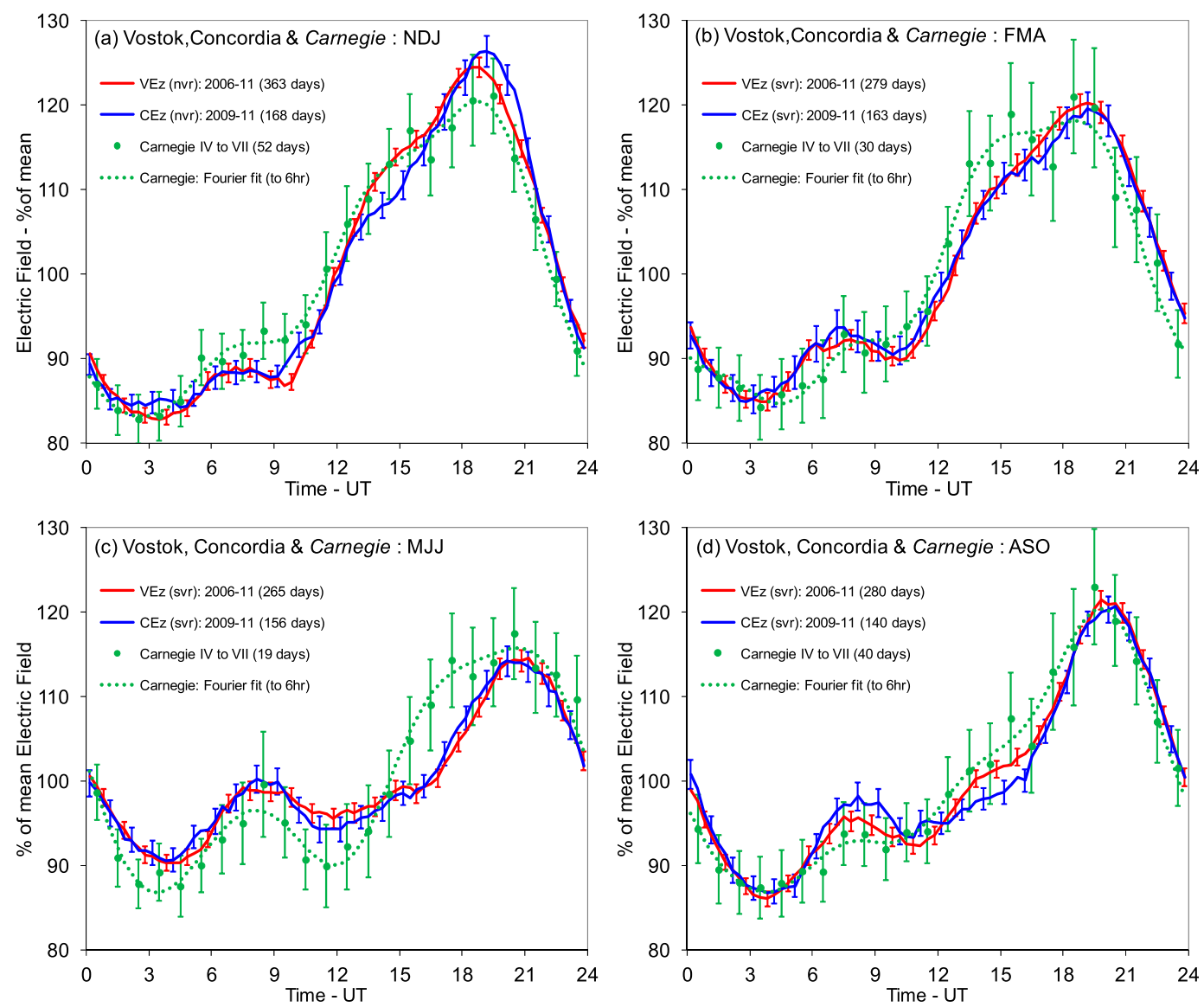

FIG. 8. Vostok (VEz), Concordia (CEz), and Carnegie seasonal plots for (a) NDJ, (b) FMA, (c) MJJ, and (d) ASO. Representative errors (plus and minus one standard error) are shown, and the amounts of data contributing (equivalent days) are listed in parentheses.

The review by Adlerman and Williams (1996) makes clear that the conclusion of a northern winter maximum based on data from the Carnegie cruises (Ault and Mauchly 1926; Torreson et al. 1946) is flawed, and that more recent observations, especially those from Mauna Loa, Hawaii, imply a northern summer maximum, consistent with theoretical expectations from the greater Northern Hemisphere land area. Further support comes from satellite observations of global lightning occurrence (Bailey et al. 2007).

For the present Vostok and Concordia observations, the estimated uncertainty in the large temperature adjustment precludes statistical significance between diurnal-mean Vostok winter and summer electric field magnitudes (Burns et al. 2012). However, the average monthly diurnal curves are significantly different whenever the difference at a particular time exceeds twice the square root of the sum of the squares of the standard errors. As noted earlier, this occurs for the Carnegie NDJ and JJA percentage of the mean diurnal averages selected by the early investigators. Statistically significant differences are obtained in all Vostok adjacent-month comparisons in Fig. 9, excluding January-February and October-November.

The influences of SWIP and local meteorology on the monthly diurnal averages are quantified in Table 2. Monthly diurnal ranges of the corrected- $E_{z}$, SWIP, and local meteorological influences are tabulated as a percentage of the electric field monthly means. Monthly averaged error estimates indicate the importance of the SWIP and meteorological corrections. SWIP corrections are substantial across all months, with the diurnal range larger across the austral summer months when the Southern Hemisphere is tilted more strongly into the solar wind. The electric field sensitivity to temperature and wind speed variations is stronger in the winter months (Burns et al. 2012). This leads to the largest meteorological influences occurring in the months with diurnal temperature variations and a low average temperature: March and October. The meteorological influences are smallest across the winter months, April-August, when the diurnal 

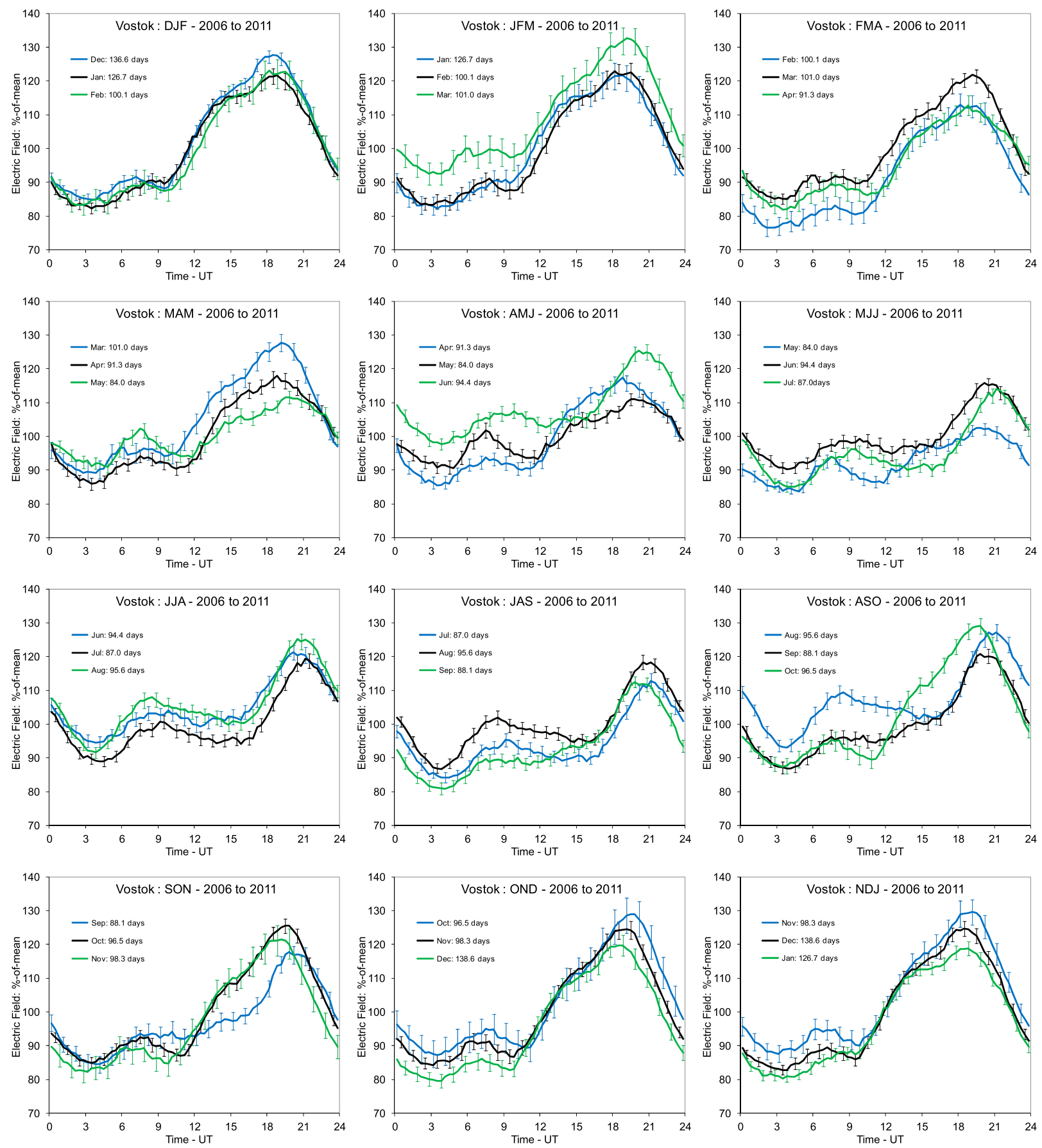

FIG. 9. Vostok monthly diurnal averages corrected for SWIP and adjusted for local meteorological influences (black). Prior (blue) and subsequent (green) months are also shown, adjusted to the temperature and percentage of the mean of the central month. Indicative errors (plus and minus one standard error) are plotted.

variations of the averaged meteorological parameters are smallest.

The simultaneous Vostok and Concordia measurements of the electric field allow us to evaluate the standard deviation of the SWIP-corrected Vostok electric field values about the appropriate best-fit line (see Fig. 4 and associated comments). Table 3 lists the seasonal and annual averages for the standard deviations about the best-fit-line SWIP-corrected- $E_{z}$ and the standard deviations about the monthly means of the 
TABLE 2. Monthly diurnal ranges of the corrected Vostok $E_{z}$, solar wind-imposed potential (SWIP), and local meteorological influences (met.), all listed as percentages of the diurnal electric field mean. Standard errors for the corrected electric field data are also shown.

\begin{tabular}{|c|c|c|c|c|}
\hline \multirow[b]{2}{*}{ Month } & \multicolumn{2}{|c|}{ Corrected $E_{z}$} & \multirow{2}{*}{$\begin{array}{l}\text { SWIP } \\
\text { diurnal } \\
\text { range }\end{array}$} & \multirow{2}{*}{$\begin{array}{l}\text { Met. } \\
\text { diurnal } \\
\text { range }\end{array}$} \\
\hline & $\begin{array}{l}\text { Diurnal } \\
\text { range }\end{array}$ & $\begin{array}{l}\text { Standard } \\
\text { error }\end{array}$ & & \\
\hline Jan & 39.3 & 2.0 & 10.0 & 1.8 \\
\hline Feb & 39.5 & 2.3 & 10.2 & 2.3 \\
\hline Mar & 36.8 & 1.9 & 7.7 & 3.6 \\
\hline Apr & 32.1 & 2.1 & 7.1 & 0.9 \\
\hline May & 20.4 & 2.0 & 6.8 & 1.3 \\
\hline Jun & 25.5 & 1.9 & 6.8 & 1.4 \\
\hline Jul & 30.4 & 1.9 & 6.9 & 1.5 \\
\hline Aug & 31.8 & 1.8 & 5.6 & 0.7 \\
\hline Sep & 34.0 & 1.9 & 6.8 & 2.6 \\
\hline Oct & 40.6 & 1.8 & 8.1 & 4.6 \\
\hline Nov & 40.3 & 2.0 & 9.5 & 2.3 \\
\hline Dec & 41.8 & 1.8 & 9.0 & 1.6 \\
\hline
\end{tabular}

SWIP-corrected- $E_{z}$, SWIP, temperature, wind speed, and pressure for the Vostok svr subset of simultaneouswith-Concordia data, each expressed as a percentage of the monthly mean electric field for direct comparison. The improvement from the svr subset corrected-forSWIP $E_{z}$ standard deviation (annual average of $16.6 \%$ ) to the standard deviation from the appropriate best-line simultaneous data fit (annual average of $11.2 \%$ ) is an unresolvable combination of the reduction due to the globally uniform contribution of the meteorological convective-electrical component of the atmospheric circuit and the similarity of the atmospheric columns at Vostok and Concordia. We can presently only account for local variability in the stably stratified lower atmosphere using average corrections for local meteorological conditions. The Vostok electric field variability that cannot be accounted for by the SWIP and average meteorological corrections is listed in the rightmost column of Table 3 (annual average of $10.7 \%$ ). This unaccounted for local variability, determined using the dual-site measurements, quantifies that statistical averages are generally needed to extract the atmospheric circuit from electric field measurements.

\section{Conclusions}

Atmospheric electric field measurements from the Concordia and Vostok stations, separated by $560 \mathrm{~km}$ on the Antarctic Plateau, show similar diurnal variations on average, and on some individual days, when data are selected to remove rapid ( $5 \mathrm{~min}$ ) variability at each site, and when corrected for the solar wind-imposed ionospheric potential above each site. A 5-day sequence of dual-site observations shows near-simultaneous variations from day to day. This is strong evidence for global representativeness of the data. Changes in the shape of the diurnal variation within the 5-day sequence, and on other individual days of near-simultaneous variations, can be interpreted as due to changes in the relative upward current output of the electrified cloud generators of the global circuit, predominantly at low latitudes.

Different levels of rejection of short period variability have been imposed on the electric field data, and for simultaneous measurements at both sites (excluding a few hours around noon in the summer months) linear regression shows stronger covariability (larger $R$-squared values) for the strongest rejection of the short-term variations, consistent with this variability being local to the station.

Around local noon in the summer months, there are rapid electric field variations, confirmed to be of local origin by the time displacement of local noon between Concordia and Vostok. The rapid summer-noon variations at Concordia occur in the interval of local convective turbulence reported for that station by Casasanta et al. (2014). Across the months of December and January, with the strongest boundary layer convective turbulence influence, the Vostok and Concordia diurnal averages show that near local noon the strongest of the data-rejection selections not only lead to greatly

TABLE 3. Seasonal and annual averages of the standard deviation of the SWIP corrected $\left(E_{z}-\mathrm{SWIP}\right)$ about the appropriate best-fit line (Fig. 4; std dev bf) and for the standard deviations about the monthly means (std dev) for the SWIP-corrected, SWIP, temperature, wind, and pressure data for the Vostok svr subset of simultaneous-with-Concordia data, each expressed as a percentage of the monthly mean electric field.

\begin{tabular}{lccccccc}
\hline \hline Season & \multicolumn{2}{c}{$E_{z}-$ SWIP } & & Temperature \\
std dev & Std dev bf & Std dev & SWIP std dev & $\begin{array}{c}\text { Wind speed } \\
\text { std dev }\end{array}$ & $\begin{array}{c}\text { Pressure } \\
\text { std dev }\end{array}$ & $\begin{array}{c}\text { Unaccounted variability } \\
\text { std dev }\end{array}$ \\
\hline NDJ & 10.3 & 17.7 & 6.2 & 0.8 & 0.6 & 1.1 & 1.0 \\
FMA & 12.5 & 17.2 & 6.5 & 1.8 & 2.0 & 1.0 & 1.2 \\
JJA & 11.4 & 16.8 & 5.9 & 3.3 & 3.6 & 1.5 & 1.2 \\
ASO & 10.7 & 14.5 & 4.8 & 2.9 & 1.3 & 1.2 & 10.1 \\
Avg & 11.2 & 16.6 & 5.6 & 2.2 & 1.9 & 10.7 \\
\hline
\end{tabular}


reduced sampling, but also to lower and more irregular average electric field values. A possible explanation of this is that the lower averages are due to short-term rapid increases being rejected more than short-term rapid decreases. Whatever the cause, a better match between average diurnal variations at Vostok and Concordia for this summer-noon period is found when less stringent rejection criteria are used.

Using linear regressions we have quantified the differences between simultaneous Vostok and Concordia electric field measurements. These are due to variations in the solar wind-imposed ionospheric potential and due to local meteorological influences. Local influences implied by these differences mean statistical analyses provide greatest reliability when using electric field measurements for insights into variability in the atmospheric circuit. This does not preclude using appropriately analyzed electric field measurements to obtain good time resolution. As stated in the appendix, variability about a running mean, using sufficient data, can determine the average time delay between solar wind input and surface field response to an accuracy of a few minutes [using the procedure detailed in Burns et al. (2012)].

Monthly diurnal averages of the Vostok electric field data adjusted for the solar wind influence and average local meteorological influences show that the relative intensities of the electrified cloud generators of the global circuit change most rapidly across AugustOctober and April-June and are most stable across December-February and June-August.

Modern Antarctic Plateau electric field datasets provide increased resolution compared to the Carnegie data; and can be compared with simultaneous, modern global meteorological datasets to further investigate the meteorological-electrical drivers of the atmospheric circuit (e.g., Mezuman et al. 2014; Hutchins et al. 2014; Liu et al. 2010). There are several tens of individual days of simultaneous dual-site observations with high daily covariability (high $R$-squared values), which provide confidence for the global representativeness of the changes in the shape of the diurnal variation for use in such comparisons.

Further electric field measurements are desirable for sites in the Arctic to provide for better continuity in monitoring changes in the global ionospheric potential.

Acknowledgments. This research was approved by the Australian Antarctic Science Advisory Committee (AAS 974). It is supported by the National Science Foundation (Award AGS0855351 to the University of Texas at Dallas). Measurements of the atmospheric electric field and AWS data at Vostok station are ob- tained in the framework of the Russian Federal Program: World Ocean: Study and Research in Antarctica: Determination of Changes in the Antarctic Environment: Environmental Monitoring. The Vostok measurements were collected by specialists of the Russian Antarctic program. The Concordia electric field data collection was approved by IPEV/PNRA via "Electricite Atmospherique DC 33 N." Concordia meteorological data were provided by IPEV/PNRA project "Routine Meteorological Observations at Station Concordia," which is financially supported by PNRA through collaboration with ENEA. Lloyd Symons, Peter Jansen, and Eric King (deceased), Australian Antarctic Division, contributed to the design, development, testing, and deployment of the electric field mill instrumentation. Solar wind parameters and magnetic coordinates were obtained from the National Space Science Data Center OMNIWeb database (http:// omniweb.gsfc.nasa.gov/form/omni_min.html) and the auroral indices from the linked access to the World Data Centre for Geomagnetism, Kyoto (http://wdc. kugi.kyoto-u.ac.jp/aeasy/index.html). Daniel Weimer's models were obtained via the CEDAR database.

\section{APPENDIX}

\section{Vostok and Concordia $E_{z}$ Responses to the Solar Wind-Imposed Potential Difference}

We compare variations in 20-min averages of the Vostok electric field measurements with variations in the solar wind-imposed potential (SWIP) above the station calculated using the Weimer (2001) model from 20-min averages of the solar wind components, separately for the strong variability rejection (svr), medium variability rejection (mvr), and no variability rejection (nvr) data selections (described in section 3 ) using the process and timing alignment described below. Diurnal variations in the atmospheric circuit are largely driven by global meteorological convective-electrical activity, which is UT aligned. SWIP variations are dominated by the polar station's rotation beneath a dawn-to-dusk pattern and are aligned to magnetic local time. The diurnal variations associated with these independent drivers must be removed before the influence of SWIP on electric field $E_{z}$ can be determined. Diurnal variations are removed from the Vostok $E_{z}$ and the SWIP above the station $V_{s}$ at each time by calculating difference values $\left(\Delta E_{z}\right.$ and $\left.\Delta V_{s}\right)$ with respect to \pm 15 -day running means of simultaneous values $\left(E_{z_{-} \text {mean }}\right.$ and $\left.V_{s_{-} \text {mean }}\right)$ at that UT time. All data are then combined into $\Delta E_{z}$ and $\Delta V_{s}$ series, separately for each of the three data selections: 


$$
\Delta E_{z}(t)=E_{z}(t)-E_{z \_ \text {mean }}(t)
$$

for the Vostok electric field and

$$
\Delta V_{s}(t)=V_{s}(t)-V_{s_{-} \text {mean }}(t)
$$

for the SWIP above Vostok.

A 30-day window is selected as a compromise for values that also vary seasonally, for which a short averaging interval is desirable, and the need for sufficient measurements to determine a valid mean. At least 10 values are required for each mean.

Time delays between the solar wind arrival at the noon magnetopause and the SWIP influence on the 2006-11 Vostok $E_{z}$ data ( $23 \mathrm{~min}$ ) and the 2009-11 Concordia $E_{z}$ measurements $(\sim 24 \mathrm{~min})$ were calculated using the offset-comparison method described in Burns et al. (2012). For the results presented here, a delay in the influence of the solar wind at the noon magnetopause upon the $E_{z}$ of $20 \mathrm{~min}$ is applied for the SWIP comparison with the Vostok and Concordia electric field measurements.

A linear regression analysis is used to compare the appropriately delayed, model-derived $\Delta V_{s}$ values with $\Delta E_{z}$. Standard errors are proportional to the square root of the number of independent data points. Standard errors are estimated assuming an independent data point for each separate day contributing to the analysis, similar to Burns et al. (2005). Significance is determined by the magnitude of the ratio of the linear regression gradient to the standard error, the $t$ statistic. When there are more than 60 independent samples, a $t$ statistic greater than 2 is significant to better than the $95 \%$ confidence level.

Linear regressions between each of the $\Delta E_{z}\left(\mathrm{~V} \mathrm{~m}^{-1}\right)$ Vostok data selections [ $\operatorname{Vos} E_{z}^{s} ; 72513$ data points (dp); 1809 independent data points (idp), Vos $E_{z}^{m} ; 88678 \mathrm{dp}$; $1830 \mathrm{idp}$ and $\left.\operatorname{Vos} E_{z}^{n} ; 92707 \mathrm{dp} ; 1830 \mathrm{idp}\right]$ and $\Delta V_{s}(\mathrm{kV})$ above Vostok yield the following results:

$$
\begin{aligned}
\operatorname{Vos} E_{z}^{s}: \Delta E_{z}= & \left(0.667 \pm 0.045 \mathrm{~V} \mathrm{~m}^{-1} \mathrm{kV}^{-1}\right) \\
& \times \Delta V_{s} ; 14.75 t \text { stat }, \\
\text { Vos } E_{z}^{m}: \Delta E_{z}= & \left(0.639 \pm 0.045 \mathrm{~V} \mathrm{~m}^{-1} \mathrm{kV}^{-1}\right) \\
& \times \Delta V_{s} ; 14.30 t \text { stat, and } \\
\text { Vos } E_{z}^{n}: \Delta E_{\mathrm{z}}= & \left(0.620 \pm 0.045 \mathrm{~V} \mathrm{~m}^{-1} \mathrm{kV}^{-1}\right) \\
& \times \Delta V_{s} ; 13.88 t \text { stat. }
\end{aligned}
$$

The $t$ statistics $(t$ stat) indicate that the electric field variations for each of the three data selections are all strongly statistically correlated to variations in the ionospheric potential difference $(t$ stat $>13.8)$. However, the reduction in the $t$ statistic as the variability criterion is relaxed and removed shows that the less restrictive datasets add measurements of reduced quality.

Correlation gradients between $\Delta E_{z}$ and $\Delta V_{s}$ determined for values that pass the weaker criteria but not the strongest criterion (i.e., pass mvr not svr selection, denoted $\operatorname{Vos} E_{z}^{m n s} ; 16165 \mathrm{dp} ; 1417$ idp or pass nvr not svr, denoted Vos $E_{z}^{\text {nns }} ; 20194$ dp; 1418 idp) are

$$
\begin{aligned}
\operatorname{Vos} E_{z}^{m n s}: \Delta E_{z}= & \left(0.525 \pm 0.048 \mathrm{~V} \mathrm{~m}^{-1} \mathrm{kV}^{-1}\right) \\
& \times \Delta V_{s} ; 10.86 t \text { stat and } \\
\operatorname{Vos} E_{z}^{n n s}: \Delta E_{z}= & \left(0.488 \pm 0.049 \mathrm{~V} \mathrm{~m}^{-1} \mathrm{kV}^{-1}\right) \\
& \times \Delta V_{s} ; \quad 10.01 t \text { stat }
\end{aligned}
$$

The $\Delta E_{z}$ and $\Delta V_{s}$ regression for values in the nvr but not the mvr data selection $\left(E_{z}^{n n m} ; 4029 \mathrm{dp} ; 727 \mathrm{idp}\right)$ yields

$$
\begin{aligned}
\operatorname{Vos} E_{z}^{n n m}: \Delta E_{z}= & \left(0.337 \pm 0.06 \mathrm{~V} \mathrm{~m}^{-1} \mathrm{kV}^{-1}\right) \\
& \times \Delta V_{s} ; 5.11 t \text { stat }
\end{aligned}
$$

Thus the extra Vostok $E_{z}$ data that pass the less restrictive selection criteria still significantly respond to the solar wind-imposed ionospheric potential, but the correlation coefficient also reduces as the quality of the electric field data reduces.

The following linear regressions are obtained comparing separate Weimer (2001) model $\Delta V_{s}$ series determined with (W01\&AL) or without (W2001) using the AL auroral activity index option, with the highest quality Vostok $\Delta E_{z}$ data $\left(\operatorname{Vos} E_{z}^{s}, \mathrm{Vm}^{-1} ; 72513 \mathrm{dp}\right.$; 1809 idp):

$$
\begin{aligned}
\text { W01\&AL: } \Delta E_{z}= & \left(0.654 \pm 0.045 \mathrm{~V} \mathrm{~m}^{-1} \mathrm{kV}^{-1}\right) \\
& \times \Delta V_{s} ; 14.58 t \text { stat and } \\
\text { W2001: } \Delta E_{z}= & \left(0.667 \pm 0.045 \mathrm{~V} \mathrm{~m}^{-1} \mathrm{kV}^{-1}\right) \\
& \times \Delta V_{s} ; 14.75 t \text { stat }
\end{aligned}
$$

There is no improvement applying the AL auroral activity index at this high-magnetic-latitude site $\left(83.6^{\circ} \mathrm{S}\right.$ mag.); the $t$ statistic reduces. A similar result is obtained with the Concordia $\left(89.0^{\circ} \mathrm{S}\right.$ mag.) electric field data. This confirms, with an independent Vostok dataset and for a higher-magnetic-latitude site (Concordia), a result obtained using earlier era Vostok data (Burns et al. 2012). Thus the Weimer (2001) model auroral activity option does not improve the match with ground-level electric field measurements at these highmagnetic-latitude sites. 
An independent estimate of the Vostok $E_{z}$ response to the ionosphere-to-Earth potential difference is obtained by dividing the annual-average Vostok $E_{z}\left(153 \mathrm{~V} \mathrm{~m}^{-1}\right)$ by the average potential difference of the meteorological generators $(240 \mathrm{kV}$; Markson 2007). The value obtained $\left(0.635 \mathrm{~V} \mathrm{~m}^{-1} \mathrm{kV}^{-1}\right)$ is within the uncertainty of the Vostok $\Delta E_{z}$ and $\Delta V_{s}$ correlation coefficient for the best data [Vos $E_{z}^{s}: 0.667 \pm 0.045 \mathrm{~V} \mathrm{~m}^{-1} \mathrm{kV}^{-1}$; Eq. (A3)]. The experimentally determined coefficient $\left(0.667 \mathrm{~V} \mathrm{~m}^{-1} \mathrm{kV}^{-1}\right)$ is used with the Weimer model-calculated value to correct the Vostok $E_{z}$ for the solar wind influence on the local ionospheric potential difference.

Figure A1 shows the diurnal averages of two Vostok data selections (Vos $E_{z}^{s}$ and $\operatorname{Vos} E_{z}^{n}$ ) across the months, which do not show any specific local-noon influence [March-October (MAMJJASO)]. These averages are derived from Vostok $E_{z}$ data corrected for the local solar wind influence. Separately averaged and displayed are data from the Vostok nvr dataset that are not in the svr dataset. The top panel uses absolute values $\left(\mathrm{V} \mathrm{m}^{-1}\right)$ and the bottom panel shows percentage of the mean values. The diurnal mean exclusive to the least restrictive data selection is $13 \mathrm{~V} \mathrm{~m}^{-1}$ greater than for the svr selection. However, broadly similar diurnal-average curves are obtained when plotted as percentages of the mean.

The $3 \mathrm{yr}$ of Concordia $E_{z}$ data (2009-11) were similarly tested for their response to the Weimer (2001) SWIP above Concordia. The following regressions are obtained comparing Concordia $\Delta E_{z}\left(\mathrm{~V} \mathrm{~m}^{-1}\right)$ determined from the three separate data selections (Con $E_{z}^{s} ; 36736 \mathrm{dp} ; 948 \mathrm{idp}$, Con $E_{z}^{m} ; 48937 \mathrm{dp} ; 976$ idp and Con $E_{z}^{n} ; 52302 \mathrm{dp}$; 978 idp) with $\Delta V_{s}(\mathrm{kV})$ above Concordia:

$$
\text { Con } \begin{aligned}
E_{z}^{s}: \Delta E_{z}= & \left(0.713 \pm 0.064 \mathrm{~V} \mathrm{~m}^{-1} \mathrm{kV}^{-1}\right) \\
& \times \Delta V_{s} ; 11.09 t \text { stat, }
\end{aligned}
$$

Con $E_{z}^{m}: \Delta E_{z}=\left(0.653 \pm 0.062 \mathrm{~V} \mathrm{~m}^{-1} \mathrm{kV}^{-1}\right)$

$$
\times \Delta V_{s} ; 10.49 t \text { stat, }
$$

and

Con $E_{z}^{n}: \Delta E_{z}=\left(0.635 \pm 0.063 \mathrm{Vm}^{-1} \mathrm{kV}^{-1}\right)$

$$
\times \Delta V_{s} ; 10.11 t \text { stat }
$$

The $t$ statistics indicate that the three Concordia selections are all strongly statistically correlated to variations in the ionospheric potential difference $(t$ stat $>10)$ and that the selection criterion with the strongest rejection of rapidly varying values (Con $E_{z}^{s}$ ) has the strongest association $(t$ stat $=11.09)$.

The Concordia annual-average electric field $\left(175 \mathrm{~V} \mathrm{~m}^{-1}\right)$ divided by the average potential difference of the
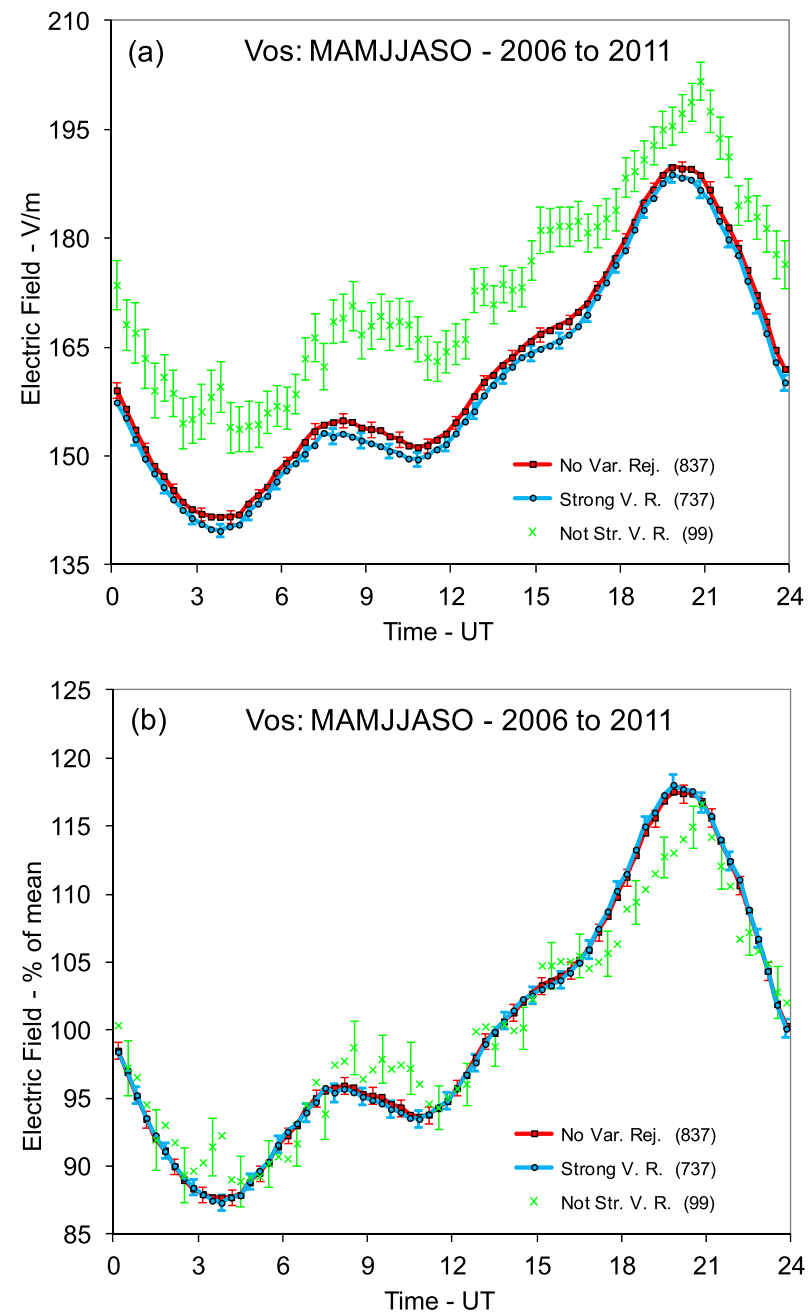

FIG. A1. Diurnal averages of Vostok electric field values for the MAMJJASO months, after correction for the solar wind influence for the indicated data selections. Values are given (a) in $\mathrm{V} \mathrm{m}^{-1}$ and (b) as a percentage of the mean. Error bars are plus and minus error in the mean. The amount of data, in equivalent days, is indicated in parentheses.

meteorological generators $(240 \mathrm{kV}$; Markson 2007) yields $0.730 \mathrm{~V} \mathrm{~m}^{-1} \mathrm{kV}^{-1}$. This is within the uncertainty of the Concordia $\Delta E_{z}$ and $\Delta V_{s}$ correlation coefficient for the svr data [Con $E_{z}^{s}$ : $0.713 \pm 0.064 \mathrm{~V} \mathrm{~m}^{-1} \mathrm{kV}^{-1}$; Eq. (A13)]. This experimentally determined coefficient $\left(0.713 \mathrm{~V} \mathrm{~m}^{-1} \mathrm{kV}^{-1}\right)$ is used with the Weimer model to remove the solar wind influence from the Concordia electric field measurements.

We compared the Concordia data selections across the months excluding the summer-noon variability (MAMJJASO) in the manner described for the Vostok data and obtained similar results. The diurnal mean of data exclusive to the least restrictive selection (Con $E_{z}^{n}$ ) is $12 \mathrm{~V} \mathrm{~m}^{-1}$ larger than for the Con $E_{z}^{s}$ diurnal mean; and broadly similar Concordia diurnal-average curves were 
obtained when expressed as percentages of the mean. There is less Concordia data (2009-11) than Vostok data (2006-11), and a Concordia plot is not included.

Claims and inferences in this paragraph refer to the Vostok plots in Fig. A1 and follow on from reporting similar results at Concordia. The larger $E_{z}$ values accepted by the nvr criterion are evenly distributed across the day; allowing that $\sim 95 \%$ of the data should fall within twice the standard error. We hypothesize that the larger values included in the nvr selections may be associated with wind-lifted-snow or "diamond dust" events that do not trigger the "too large value" rejection criterion. These events are of local origin and likely increase the $E_{z}$ values, accounting for the reduced association of the less-stringent data selections with the solar wind potential imposed on the ionosphere.

\section{REFERENCES}

Adlerman, E. J., and E. R. Williams, 1996: Seasonal variation of the global electric circuit. J. Geophys. Res., 101, 29 679-29688, doi:10.1029/96JD01547.

Argentini, S., I. Pietroni, G. Mastrantonio, A. P. Viola, G. Dargaud, and I. Petrenko, 2014: Observations of near surface wind speed, temperature and radiative budget at Dome C, Antarctic Plateau during 2005. Antarct. Sci., 26, 104 112, doi:10.1017/S0954102013000382.

Ault, J. P., and S. J. Mauchly, 1926: Ocean Magnetic and Electric Observations, 1915-1921. Researches of the Department of Terrestrial Magnetism, Vol. 5, Carnegie Institution of Washington, $448 \mathrm{pp}$.

Bailey, J. C., R. J. Blakeslee, D. E. Buechler, and H. J. Christian, 2007: Diurnal lightning distributions as observed by the Optical Transient Detector (OTD) and the Lightning Imaging Sensor (LIS). Proceedings of the 13th International Conference on Atmospheric Electricity, X. Qie and C. Saunders, Eds., Vol. II, Elsevier, 657-660. [Available online at https://ntrs.nasa.gov/ archive/nasa/casi.ntrs.nasa.gov/20070038367.pdf.]

Bering, E. A., III, A. A. Few, and J. R. Benbrook, 1998: The global electric circuit. Phys. Today, 51, 24-30, doi:10.1063/1.882422.

Boucher, O., and Coauthors, 2013: Clouds and aerosols. Climate Change 2013: The Physical Science Basis, T. F. Stocker et al., Eds., Cambridge University Press, 571-657.

Burns, G. B., M. H. Hesse, S. K. Parcell, S. Malchowski, and K. D. Cole, 1995: The geoelectric field at Davis station, Antarctica. J. Atmos. Terr. Phys., 57, 1783-1797, doi:10.1016/0021-9169(95)00098-M.

— A. A. Frank-Kamenetsky, O. A. Troshichev, E. A. Bering, and B. D. Reddell, 2005: Interannual consistency of bimonthly differences in diurnal variations of the ground-level, vertical electric field. J. Geophys. Res., 110, D10106, doi:10.1029/ 2004JD005469.

—, B. A. Tinsley, W. J. R. French, O. A. Troshichev, and A. V. Frank-Kamenetsky, 2008: Atmospheric circuit influences on ground-level pressure in the Antarctic and Arctic. J. Geophys. Res., 113, D15112, doi:10.1029/2007JD009618.

, - A. V. Frank-Kamenetsky, O. A. Troshichev, W. J. R. French, and A. R. Klekociuk, 2012: Monthly diurnal global atmospheric circuit estimates derived from Vostok electric field measurements adjusted for local meteorological and solar wind influences. J. Atmos. Sci., 69, 2061-2082, doi:10.1175/ JAS-D-11-0212.1.

Casasanta, G., I. Pietroni, and I. Petenko, 2014: Observed and modelled convective mixing-layer height at Dome C, Antarctica. Bound.-Layer Meteor., 151, 597-608, doi:10.1007/ s10546-014-9907-5.

Corney, R. C., and Coauthors, 2003: The influence of polar-cap convection on the geoelectric field at Vostok, Antarctica. J. Atmos. Sol.-Terr. Phys., 65, 345-354, doi:10.1016/ S1364-6826(02)00225-0.

Hutchins, M. L., R. H. Holzworth, and J. B. Brundell, 2014: Diurnal variation of the global electric circuit from clustered thunderstorms. J. Geophys. Res. Space Phys., 119, 620-629, doi:10.1002/2013JA019593.

Israel, H., 1973: Atmospheric Electricity. Israel Program for Scientific Translations, $796 \mathrm{pp}$.

Kleimenova, N. G., O. V. Kozyreva, M. Kubicki, and S. Michnowski, 2011: Substorm effects in the polar latitude atmospheric electric field disturbances. Proc. XXXIII Annual Seminar, Apatity, Russia, Polar Geophysical Institute, 167170. [Available online at http://pgia.ru:81/seminar/archive/ 2010/6_atmosphere/06-02_Kleimenova.pdf.]

Lam, M. M., G. Chrisham, and M. P. Freeman, 2013: The interplanetary magnetic field influences mid-latitude surface atmospheric pressure. Environ. Res. Lett., 8, 045001, doi:10.1088/ 1748-9326/8/4/045001.

Liu, C., E. R. Williams, E. J. Zipser, and G. Burns, 2010: Diurnal variations of global thunderstorms and electrified shower clouds and their contribution to the global electric circuit. J. Atmos. Sci., 67, 309-323, doi:10.1175/ 2009JAS3248.1.

Mansurov, S. M., L. G. Mansurova, G. S. Mansurov, V. V. Mikhenvich, and A. M. Visotsky, 1974: North-south asymmetry of geomagnetic and tropospheric events. J. Atmos. Terr. Phys., 36, 1957-1962, doi:10.1016/0021-9169(74)90182-2.

Markson, R., 1978: Solar modulation of atmospheric electrification and possible implications for the Sun-weather relationship. Nature, 273, 103-109, doi:10.1038/273103a0.

_ 2007: The global circuit intensity: Its measurement and variation over the last 50 years. Bull. Amer. Meteor. Soc., 88, 223 241, doi:10.1175/BAMS-88-2-223.

Mezuman, K., C. Price, and E. Galanti, 2014: On the spatial and temporal distribution of global thunderstorm cells. Environ. Res. Lett., 9, 124023, doi:10.1088/1748-9326/9/12/ 124023.

Park, C. G., 1976: Downward mapping of high-latitude ionospheric electric fields to the ground. J. Geophys. Res., 81, 168-174, doi:10.1029/JA081i001p00168.

Reddell, B. D., J. R. Benbrook, E. A. Bering, E. N. Cleary, and A. A. Few, 2004: Seasonal variations of atmospheric electricity measured at Amundsen-Scott South Pole station. J. Geophys. Res., 109, A09308, doi:10.1029/2004JA010536.

Rycroft, M. J., R. G. Harrison, K. A. Nicoll, and E. A. Mareev, 2008: An overview of Earth's global electric circuit and atmospheric conductivity. Space Sci. Rev., 137, 83-105, doi:10.1007/ s11214-008-9368-6.

Tinsley, B. A., 2008: The global atmospheric electric circuit and its effect on cloud microphysics. Rep. Prog. Phys., 71, 066801, doi:10.1088/0034-4885/71/6/066801.

2012: A working hypothesis for connections between electrically-induced changes in cloud microphysics and storm vorticity, with possible effects on circulation. Adv. Space Res., 50, 791-805, doi:10.1016/j.asr.2012.04.008. 
, and R. A. Heelis, 1993: Correlations of atmospheric dynamics with solar activity evidence for a connection via the solar wind, atmospheric electricity, and cloud microphysics. J. Geophys. Res., 98, 10 375-10 384, doi:10.1029/93JD00627.

Torreson, O. W., W. C. Parkinson, O. H. Gish, and G. R. Wait, 1946: Scientific results of cruise VII of the Carnegie during 1928-1929, ocean atmospheric-electric results. Carnegie Institute of Washington Publ. 568, 178 pp.

Weimer, D. R., 1996: A flexible, IMF dependent model of highlatitude electric potentials having "space weather" applications. Geophys. Res. Lett., 23, 2549-2552, doi:10.1029/96GL02255.

,2001: An improved model of ionospheric electric potentials including substorm perturbations and application to the Geospace
Environment Modelling November 24, 1996, event. J. Geophys. Res., 106, 407-416, doi:10.1029/2000JA000604.

Whipple, F. J. W., and F. J. Scrase, 1936: Point discharge in the electric field of the earth: An analysis of continuous records obtained at Kew Observatory. Geophysical Memoirs 68, HMSO Meteorological Office, 24 pp.

Williams, E. R., 2005: Lightning and climate: A review. Atmos. Res., 76, 272-287, doi:10.1016/j.atmosres.2004.11.014.

Wilson, C. T. R., 1921: Investigations on lightning discharges and the electric field of thunderstorms. Philos. Trans. Roy. Soc. London, A221, 73-115, doi:10.1098/rsta.1921.0003.

Zhou, L., and B. A. Tinsley, 2010: Global circuit model with clouds. J. Atmos. Sci., 67, 1143-1156, doi:10.1175/2009JAS3208.1. 